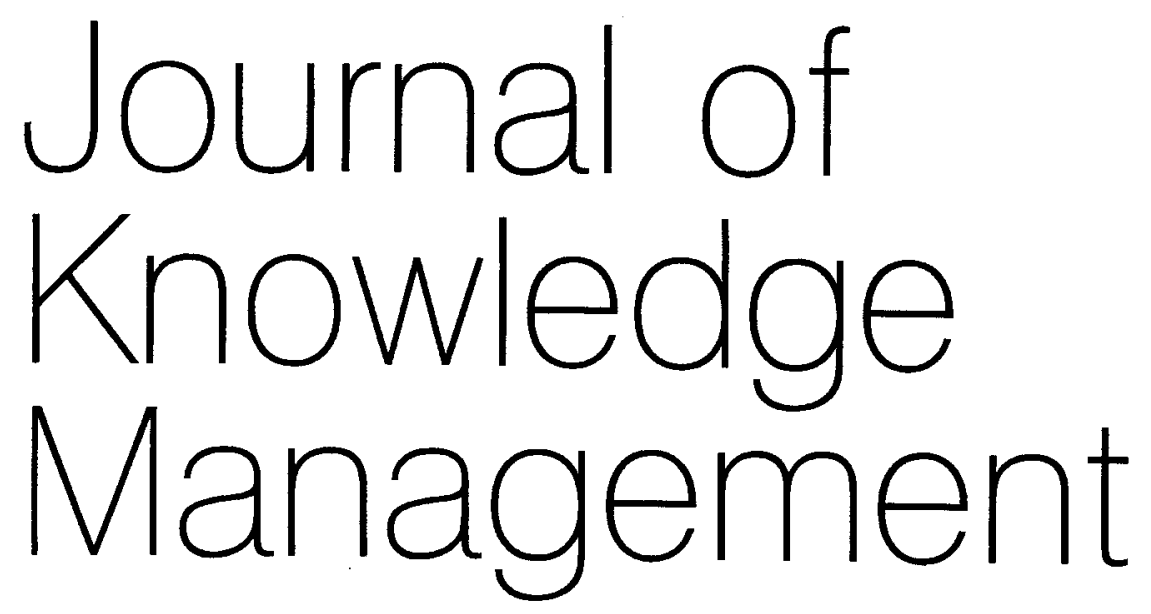

\title{
Knowledge-enabled customer relationship management: integrating customer relationship management and knowledge management concepts[1]
}

\section{Henning Gebert}

Researcher, at the Institute of Information Management, University of St Gallen, St Gallen, Switzerland

\section{Malte Geib}

Researcher, at the Institute of Information Management, University of St Gallen, St Gallen, Switzerland

\section{Lutz Kolbe}

Research Head, at the Institute of Information Management, University of St Gallen, St Gallen, Switzerland

\section{Walter Brenner}

Professor, at the Institute of Information Management, University of St Gallen, St Gallen, Switzerland

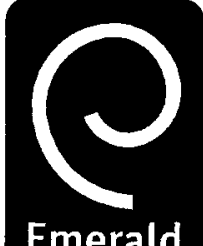

Journal of Knowledge Management, Vol. 7 No. 5, 2003,

(C) MCB UP Limited, $1367-3270$ 
Editor

Rory L. Chase

Managing Director, Teleos, UK

\section{Associate Editor}

\section{Syed Z. Shariq}

Director of Research, Knowledge: Networks, Exchange and Uses (KNEXUS) Program, Institute for International Studies, Stanford University, USA

\section{Regional Editor}

Fawzy Soliman

Course Director and Senior Lecturer in

Management, University of Technology, Sydney, Australia

\section{Conference and Events Editor \\ Jay Chatzkel}

Progressive Practices, Anthem, AZ, USA

Managing Editor

Rachel Murawa

\section{EDITORIAL BOARD}

\section{Manfred Aben}

Head. Knowledge Management Group, Unilever NV, The Netherlands

\section{Marie-Ange Andrieux}

Head of Corporate Finance, Mazars \& Guerard, France

\section{Annie Brooking}

Chief Executive Officer, Lux Inflecta, Iceland

\section{Robert H. Buckman}

Chairman of the Executive Committee of the

Board of Directors, Bulab Holdings, USA

Francisco Javier Carrillo

Director, Center for Knowledge Systems, ITESM, Mexico

\section{Steven A. Cavalerì}

Professor, Department of Management \& Organization, Central Connecticut State University, USA

\section{Leif Edvinsson}

Chief Executive Officer, Universal Networking Intellectual Capital AB, Sweden

\section{Kent A. Greenes}

Corporate Senior Vice President, Science

Applications International Inc., USA

Brian Hall Founder and Chairman, ValuesTechnology Inc.,
USA

Journal of Knowledge Management is indexed and abstracted in:

Astib - The Association for Information

Management

Emerald Reviews (formerly Anbar)

Fulltext Sources Online

Information Sciences Abstracts

INSPEC
Bipin Junnarkar

Vice President, Knowledge Management, HP Company, USA

\section{Kaisa Kautto-Koivula}

Senior Manager of Education, Learning and Knowledge Management, Nokia Ventures

Organization, Finland

\section{Seija Kulkki}

Director of Research, Centre for International Business Research, Helsinki School of Economic and Business Administration, Finland

\section{Dorothy Leonard}

William J. Abernathy Professor of Business

Administration, Harvard University, USA

Deependra Moitra

General Manager (Research), Infosys

Technologies, India

\section{Victor Newman}

Chief Learning Officer, Pfizer Global Research and Development, UK

\section{Ikujiro Nonaka}

Dean of the Graduate School of Knowledge Sciences, Hitotsubashi University, Japan; Xerox Distinguished Professor in Knowledge, Hass School of Business, University of California, Berkeley, USA

\section{Edna Pasher}

Chief Executive Officer, Edna Pasher PhD \& Associates - Management Consultants Ltd, Israel

\section{George Pór}

Founder and Senior Consultant, Communitylntelligence Ltd, France

William D. Schulte, Jr

Associate Professor, Byrd School of Business, Shenandoah University, USA

Hirotaka Takeuchi

Dean, Graduate School of International Corporate Strategy, Hitotsubashi University, Japan

Rob van der Spek

Manager Strategy and Development, Centre for Excellence CIBIT, The Netherlands

\section{Georg von Krogh}

Professor of Management, Director of the Institute of Management, University of St Gallen, Switzerland

\section{Arian Ward}

President and Chief Executive Officer, Work Frontiers International, USA

\section{Kart M. Wiig}

Chairman and Chief Executive Officer, Knowledge Research Institute, USA

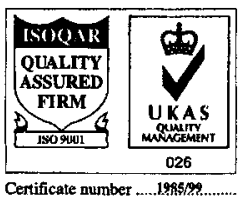

Pre-press activities, comprising origination and pagination, associated with the publication of management journals
Journal of Knowledge Management

ISSN 1367-3270

(C) 2003 MCB UP Limited

Internet services available worldwide on URL www.managementfirst.com

For customer service enquiries

ManagementFirst from Emerald

$60 / 62$ Toller Lane, Bradford.

West Yorkshire,

England BD8 $9 \mathrm{BY}$

$\mathrm{Tel}+44$ (o) 1274785151

$\mathrm{Fax}+44$ (o) 1274785200

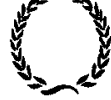

Emerald

For members of academic institutions please contact:

Tel +44 (o) 1274785151

Fax +44 (o) 1274785200

Regional offices

For North America

Emerald, 44 Brattle Street, 4th Floor.

Cambridge, MA 02138, USA

Tel Toll free +18886220075

Fax +16173546875

E-mail america@emeraldinsight.com

For Japan

Emerald, Reina 308, 5-1 Sakae-cho,

Kanagawa-ku, Yokahama City, Kanagawa

Prefecture, 221-0052 Japan

Tel +81454440388

Fax +81454440389

E-mail japan@emeraldinsight.com

\section{For Asia Pacific}

Emerald, 7-2, 7th Floor, Menara KLH, Bandar Puchong Jaya,

47100 Puchong, Selangor, Malaysia

Tel 60380766009

Fax 60380766007

E-mail asiapacific@emeraldinsight.com

Please contact the following for further information:

For general queries please e-mail info@managementfirst.com or telephone

+44 (o) 1274785151

Sample copies: +44 (o) 1274785151 or e-mail samples@managementfirst.com

All orders and subscription enquiries: Contact ManagementFirst on +44 (o) 1274785151 or e-mail sales@managementfirst.com

Missing issue claims*: +44 (o) 1274777700

*Missing issue claims will be fulfilled if claimed within four months of date of despatch.

Maximum of one claim per issue.

\section{Reprint service enquiries:}

Carole Noble, Bradford

E-mail cnoble@emeraldinsight.com

Copyright permissions:

Charles Parker, Bradford

E-mail cparker@emeraldinsight.com

ManagementFirst and Emerald are trading names of MCB UP Limited

Printed by Printhaus Group Ltd, Scirocco Close. Moulton Park, Northampton NN3 6 HE

No part of this joumal may be reproduced, stored in

a retrieval system, transmitted in any form or by any means electronic, mechanical, photocopying, recording or otherwise without either the prior written permission of the publisher or a licence permitting restricted copying issued in the UK by The Copyright Licensing Agency and in the USA by The Copyright Clearance Center. No responsibility is accepted for the accuracy of information contained in the text, illustrations or advertisements. The opinions expressed in the articles are not necessarily those of the editor or the publisher. 


\section{Knowledge-enabled customer relationship management: integrating customer relationship management and knowledge management concepts[1]}

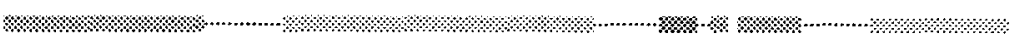

Henning Gebert, Malte Geib, Lutz Kolbe and Walter Brenner
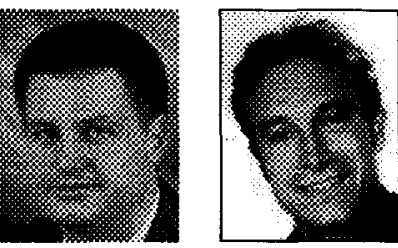

Henning Gebert is a Researcher (henning.gebert@unisg.ch), Malte Geib is a Researcher (malte.geib@unisg.ch), Lutz Kolbe is Research Head (lutz.kolbe@unisg.ch), and Walter Brenner is a Professor (walter.brenner@unisg.ch), all at the Institute of Information Management, University of St Gallen, St Gallen, Switzerland.
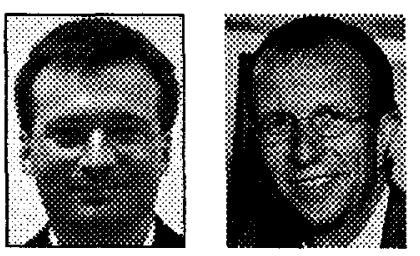

Abstract The concepts of customer relationship management (CRM) and knowledge management (KM) both focus on allocating resources to supportive business activities in order to gain competitive advantages. CRM focuses on managing the relationship between a company and its current and prospective customer base as a key to success, while KM recognizes the knowledge available to a company as a major success factor. From a business process manager's perspective both the CRM and KM approaches promise a positive impact on cost structures and revenue streams in return for the allocation of resources. However, investments in CRM and KM projects are not without risk, as demonstrated by many failed projects. In this paper we show that the benefit of using CRM and KM can be enhanced and the risk of failure reduced by integrating both approaches into a customer knowledge management (CKM) model. In this regard, managing relationships requires managing customer knowledgeknowledge about as well as from and for customers. In CKM, KM plays the role of a service provider, managing the four knowledge aspects: content, competence, collaboration and composition. Our findings are based on a literature analysis and six years of action research, supplemented by case studies and surveys.

Keywords Knowledge management, Customer relations, Process management

\section{Introduction}

The concepts of customer relationship management (CRM) and knowledge management (KM) have recently gained wide attention in business and academia. Both approaches focus on allocating resources to supportive business activities in order to gain competitive advantages. Although these concepts are currently mostly regarded as separate research areas, we see a high synergy potential in an integrated approach.

To build good relationships with customers, it is necessary to serve each customer in his preferred way, therefore requiring the management of "customer knowledge" (Davenport et al., 2001). Many knowledge management approaches, as presented by KM models, regard managing knowledge as independent of the supported business processes. Knowledge and its management are seen as inherently valuable, a view not generally shared by the process owners who have to bear the costs of the supportive activities, but are measured by their ability to generate revenue and control costs. In many cases the latter is not measured in knowledge, but in services or products (Demarest, 1997).

In this paper we show that the integration of CRM and KM concepts on a process level is beneficial to both management approaches. On the one hand, customer-oriented knowledge 


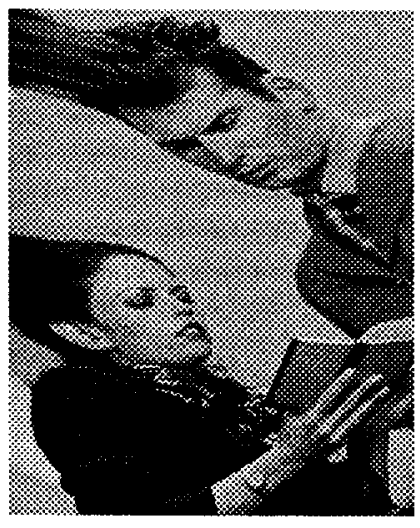

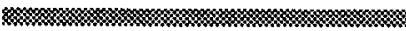

management focuses on the knowledge most valuable to the company: customer knowledge. On the other hand, knowledge-oriented customer relationship management can use a conceptual framework to manage the knowledge required for high quality relationships in a cost-effective way. We thus derived a customer knowledge management (CKM) model that describes the basic elements for successful knowledge management in customer-oriented processes. This model serves as a frame of reference for integrated CKM activities on both the enterprise and project level.

In order to integrate $\mathrm{KM}$ and $\mathrm{CRM}$ on the process level, both resource-oriented concepts should be aligned with the business-oriented process view - an alignment based on an analysis of literature. In addition, we describe the implications of the integration approach and a case study which provides tangible recommendations for practitioners.

The CKM model is based on the foundations of business engineering (BE), a research approach developed at the Institute of Information Management (IWI-HSG) at the University of St Gallen (Österle, 1995). Business engineering differentiates between strategy, process and system levels. The research described in this paper concentrates on the CRM, KM and, subsequently, CKM process level, while interdependencies with the system level are discussed at different stages.

The primary research approach was "action research" as defined by Gummesson (2000). This foundation was enriched by complementing, in-depth case studies that help to validate the research questions, align existing models with reality, and finally prompt new research challenges. The CKM model is therefore based on nearly six years of research with corporate research partners AGI (the IT service provider for cantonal Swiss banks), Asean Brown Boveri (ABB), Bank Austria, BASF, Credit Suisse, Deutsche Telekom, DKV Insurance, Helsana Insurance, the state bank of Baden-Wuerttemberg (LBBW). St Gallen cantonal bank, Swisscom IT Senvices, Union Investment and Winterthur Life \& Pensions[2].

The paper is structured into three main sections: the theoretical foundation analyzes some current approaches in the fields of CRM and KM and identifies relevant elements concerning integration. Thereafter the required modification of current approaches and the main elements of the integrated model are discussed. Finally, we describe a sample application of the model in a business environment, based on a report of the action research conducted with a corporate research partner. The paper concludes with a summary, a critical reflection and an outlook on further research opportunities.

\section{Knowledge in customer-oriented processes}

Increasing competition and decreasing customer loyalty have led to the emergence of concepts that focus on the nurturing of customer relationships. Customer relationship management (CRM) emerged as an amalgamation of different management and information system approaches, in particular relationship marketing and technology-oriented approaches such as computer aided selling (CAS) and sales force automation (SFA). Following Shaw (1999), we define CRM as an interactive process that achieves an optimum balance between corporate investments and the satisfaction of customer needs to generate the maximum profit. It entails:

- measuring both inputs across all functions - including marketing, sales and service costs and outputs in terms of customer revenue, profit and value;

- acquiring and continuously updating knowledge on customer needs, motivations and behavior over the lifetime of the relationship;

- applying customer knowledge to continuously improve performance through a process of learning from successes and failures;

- integrating marketing, sales and service activities to achieve a common goal;

- the implementation of appropriate systems to support customer knowledge acquisition, sharing and the measurement of CRM effectiveness; and

- constantly contrasting the balance between marketing, sales, and service inputs with changing customer needs in order to maximize profit. 


\section{CRM requires the strong integration of business processes which involve customers. 99}

To integrate marketing, sales, and service activities, CRM requires the strong integration of business processes which involve customers. These customer-oriented CRM processes are mostly unstructured and non-transactional, and their performance is predominantly influenced by the underlying supply of knowledge on products, markets, and customers (Day, 2000; Schulze et al., 2000; Garcia-Murillo and Annabi, 2002).

CRM processes can therefore be considered knowledge-oriented processes with the following, strongly correlated, characteristics (Eppler et al., 1999):

- Knowledge intensity - CRM processes require knowledge from heterogeneous, not necessarily computational, sources to pursue process goals.

- Process complexity - CRM processes mostly have complex structures or even no clear structure at all. This implies that a high degree of knowledge is necessary for the execution of a process.

Knowledge flows in CRM processes can be classified into three categories:

(1) Knowledge for customers is required in CRM processes to satisfy customers' knowledge needs. Examples include knowledge on products, markets and suppliers (Garcia-Murillo and Annabi, 2002).

(2) Knowledge about customers is accumulated to understand customers' motivations and to address them in a personalized way. This includes customer histories, connections, requirements, expectations, and their purchasing activity (Day, 2000; Davenport et al., 2001).

(3) Knowledge from customers is customers' knowledge of products, suppliers and markets. Through interactions with customers this knowledge can be gathered to sustain continuous improvement, e.g. service improvements or new product developments (Garcia-Murillo and Annabi, 2002).

Knowledge for customers and knowledge from customers are part of the relational intellectual capital of a firm (Ordóñez de Pablos, 2002). Managing these different knowledge flows is one of the most important challenges of CRM. In this regard, the most important issue is how to collect, store, and distribute only that knowledge which is needed and not to waste time and effort on collecting and storing useless knowledge (Davenport et al., 2001).

To identify relevant knowledge that is needed in business processes, business process engineering methods can be used (Harrington, 1991; Davenport, 1993; Hammer and Champy, 1993). In practice, process reengineering projects are often carried out to integrate different CRM processes, with these projects providing process models that can form the basis of an analysis of knowledge flows.

To determine which CRM processes need to be integrated and analyzed with regard to their knowledge needs, we analyzed the existing conceptualizations of CRM.

Current CRM approaches and process orientation

The origins of CRM can be traced back to the management concept relationship marketing (RM), with Levitt (1983) being one of the first to propose a systematic approach for the development of buyer-seller relationships. Relationship marketing can be defined as an integrated effort to identify, maintain, and build up a network with individual customers and to continuously strengthen the network for the mutual benefit of both sides through interactive, individualized and value-added contacts over a long period of time (Shani and Chalasani, 1992).

However, RM is largely strategic and as such, lacks a holistic view of the business processes connected to it, although business processes are regarded as important (Parvatiyar and Sheth, 2000). 
CRM, on the other hand, was influenced by several information systems concepts, focusing on distinct application areas. For example, computer aided selling (CAS) and sales force automation (SFA) systems are responsible for the control and automation of sales processes, whereas other systems for service or marketing automation focus on service as well as marketing processes. In the course of process integration, these systems continually merge towards integrated CRM suites.

A widely accepted classification of systems connected to CRM is the following (Schwede, 2000):

- Operational CRM systems improve the efficiency of CRM business processes and comprise solutions for sales force automation, marketing automation, and call center/customer interaction center management.

- Analytical CRM systems manage and evaluate knowledge about customers for a better understanding of each customer and his or her behavior. Data warehousing and data mining solutions are typical systems in this area.

- Collaborative CRM systems manage and synchronize customer interaction points and communication channels (e.g. telephone, e-mail, and Web).

Whereas operational CRM systems focus on the support of distinct front-office business processes, analytical and collaborative CRM systems only have a supporting role in operational CRM.

Apart from the strategy-oriented concept of RM and systems-oriented concepts, there are several CRM approaches with a specific focus on business processes (Schulze et al., 2000). Most of these approaches define marketing, sales, and service as core CRM processes, overlooking the fact that these are functional areas that have to be integrated by defining crossfunctional business processes. Others focus on specific activities, but do not propose a process framework for CRM

Our goal was to overcome these shortcomings by proposing a process model consisting of business processes that are relevant in the CRM context. This framework could then be used as a starting point for the analysis of knowledge flows in CRM processes.

\section{Status and challenges of CRM in real-world applications}

The identification of valuable prospective customers as well as the discovery of cross- and upselling opportunities within the existing customer base has been especially important for our corporate research partners. We could therefore observe an extensive use of information systems for analytical CRM within these companies. Although several companies are far advanced in the implementation of a continuous process for analytical CRM, the majority still has difficulties in managing the relevant knowledge. In particular, the challenge to ensure a consistent knowledge flow from the point of creation of knowledge about the customer (in marketing, sales, and service) to the point of action, where the knowledge has to be presented in an adequate form and complexity, is far from being solved.

Another subject of considerable relevance is the management of customer service. All the participating companies have call-centers that handle service inquiries. The provision of the right knowledge to assist call-center staff to handle inquiries within an adequate timeframe remains one of the major challenges. To address this challenge, some companies have undertaken projects for the implementation of knowledge management systems. Another future challenge is the use of multiple communication channels to address customer service needs. All companies show further potential to exploit self-service technologies with the aim of increasing senvice quality and decreasing service costs. Using these technologies will raise the question of how to synchronize different communication channels to ensure a consistent appearance towards customers.

Closely connected to service management is the handling of customer complaints. Although all our corporate research partners have a process for complaint management, many of these 
reveal shortcomings regarding the analysis and proactive utilization of complaints for continuous improvement.

The literature research and work with our corporate research partners suggested that the management of knowledge in CRM processes is a critical success factor. A CRM process model could therefore be used as starting point for an analysis and improvement of knowledge flows. However, the existing conceptualizations of CRM in the literature either lacked processorientation or could not provide a process framework for CRM that was detailed enough to suit this purpose.

\section{A review of knowledge management models}

Drucker (1999) and others speak of knowledge as "the most important resource of the twentyfirst century". To determine what kind and how much knowledge a business process requires for a top performance should be the first step in a supportive knowledge management approach (Demarest, 1997). The steady interest in knowledge management in academia and business circles alike has spawned many $\mathrm{KM}$ models that try to capture the inherent qualities as well as the dissemination and development characteristics of knowledge in order to assess the methods and techniques of managing this resource in a business environment.

While many knowledge management models offer valuable insights into the nature of knowledge, their difficulties with justifying the management of knowledge within the business environment, e.g. attaching a value to specific knowledge resources and providing guidelines concerning its use, is a point of constant criticism (Davenport and Marchand, 2001; Donahue, 2001). To understand the reason for this it is important to analyze the foundations of the modeling approaches used. Almost all knowledge management models can be traced back to a basic approach to analyze knowledge. The models either view knowledge as an entity with distinctive attributes that can be deconstructed and its details analyzed, or they view it as an integrated whole and focus on its relations with the surroundings. Within this paper the former view will be called an epistemological perspective, the latter an ontological perspective. The following analysis provides an introduction to this differentiation.

\section{Epistemology-oriented KM models}

As a philosophical research area, epistemology investigates the nature of knowledge itself. Epistemological knowledge management models therefore view knowledge as an entity that can be deconstructed into discrete, relevant attributes, based on the epistemological foundation held by the modeler.

Based on the autopoietic theory, the main differentiating characteristic of knowledge is the difficulty of its articulation. Knowledge that can be easily articulated is labeled "explicit knowledge". Knowledge, that is difficult to articulate, and therefore difficult to transfer, is labeled "tacit knowledge" (Polanyi, 1966), which has been recently superseded by the term "implicit knowledge". With their SECl model, Nonaka and Takeuchi have formulated an encompassing epistemological, autopoietic knowledge management approach (Nonaka and Konno, 1998). Other examples of epistemological-oriented knowledge management models with an autopoietic approach include the models of Boisot (1987) and McLoughlin and Thorpe (1993).

Based on their definition of knowledge, all epistemological-oriented knowledge management models share a common weakness when used in an environment that requires evaluating knowledge as a business resource. These models can only calculate the value of knowledge as based on its internal qualities, thus independent of the context in which it is used. Since the evaluation of a resource based solely on internal qualities is not sufficient for management decisions, the value of epistemological models in a business environment is limited.

\section{Almost all knowledge management models can be traced back to a basic approach to analyze knowledge. 9}

VOL. 7 NO. 52003 | JOURNAL OF KNOWLEDGE MANAGEMENT | PAGE 111 


\section{Ontology-oriented KM models}

Also based on philosophical research, ontology represents a systematic account of existence. It is an "explicit specification of a conceptualization: the objects, concepts, and other entities that are presumed to exist in some area of interest and the relationships that hold them" (Gruber, 1993).

Ontological knowiedge management models therefore define knowledge solely through their relationships with a constructed universe of discourse, encompassing all dimensions that are relevant to the modeler. They view knowledge as a "black box" with undefined inherent characteristics.

Modeling dimensions frequently used by ontological knowledge management models include a process dimension, an agent dimension (individual vs. group) and a financial dimension. The latter is based on intellectual capital research, and, due to the specific aims of the resulting models, will not be further examined within this paper.

Process-oriented KM models focus on the characteristics of knowledge during its life cycle. They analyze the relationships and environmental variables that influence the development, dissemination, modification and use of knowledge processes. Examples of process-oriented KM models include Probst et al. (1999) and Wiig (1995). Agent-oriented KM models focus on the characteristics of knowledge during its flow between individuals. They analyze the variables that expedite or hinder the flow of knowledge in social networks. Examples of agent-oriented KM models include Wenger (1997) and Enkel et al. (2000).

Ontology-oriented models analyze links between knowledge and its environment. They can therefore evaluate knowledge based on a specific business context. However, the analysis ability of ontology-oriented knowledge management models is limited by their disregard of the inherent characteristics of knowledge. While generic processes for knowledge management can be defined with a black box approach, the structure of knowledge management processes on the realization level depends on the characteristics of the knowledge being managed. For example, expenditures on knowledge management, on identifying and disseminating knowledge, depend on whether its manifestation is mainly implicit or explicit. Similar process influences can be examined in other knowledge characteristics, such as context complexity, knowledge volatility and culture. Therefore, due to their generic approach, ontology-oriented knowledge management models cannot assess the value of knowledge on an operational level.

\section{Hybridization of KM models}

Based on the strengths and weaknesses of both model types, epistemology and ontology perspectives seem to have high synergy potentials. Though it is possible to analyze the structure of an entity and its relations separately; in trying to assess the business benefits of knowledge management, both the inherent characteristics and relevant relationship variables of knowledge must be taken into account.

Most KM models developed within the last decade therefore exhibit characteristics of both views with most models revealing their origins as based on an internal imbalance between the details of epistemological and ontological viewpoints. Nonaka integrated an agent ontological dimension in 1994 (Hedlund and Nonaka, 1993) and tried to bond both views in his concept of "ba" (Nonaka and Konno, 1998). By definition Demarest's process-oriented KM model focuses on the processing of explicated knowledge (Demarest, 1997). But a fully balanced model is yet to be created (McAdam and McCreedy, 1999).

\section{The inherent value of knowledge}

As most enterprises do not survive by only managing knowledge, knowledge management is basically a support process. However, due to the pervasive nature of knowledge, any business process can be transformed into a "knowledge management process", if defined by activities such as knowledge creation, knowledge dissemination and knowledge use. Many ontological and hybrid knowledge management models allude to this view by making no clear value distinction between business processes and knowledge processes. Instead of merely supporting value generation, knowledge management processes also have inherent value 
creation capabilities. By stipulating the co-existence or substitution of existing business processes, knowledge management becomes unattractive for managers who view it as a threat to their position and resources.

We oppose the argument that knowledge and knowledge management have an inherent value. While knowledge has become more important to all business processes, it is still a resource that abides by the laws of economics: it has a diminishing marginal utility and normally its management does not directly generate business value. A change in the alignment of the KM models is required to actually tap the supportive performance of managing knowledge in a CRM environment.

\section{Knowledge management in practice}

The established gap between the self-orientation of knowledge management models and the requirements of business process owners was verified by research undertaken within our corporate research partners.

A survey (Büren et al., 2001) based on 60 questionnaires and 19 detailed telephone interviews delivered the following results: the managers require an evaluation framework that will support them in operating the content flow within and between processes and will maintain a concise and performance-oriented content base. In subsidiaries and call centers, information requirements that are driven by new CRM systems inhibit employees' service capabilities in their interaction with customers. Managers are therefore not concerned with ways in which to effectively and mutually create and disseminate knowledge. While the corporate research partners spend substantial resources on knowledge management, their managers are trying to control the exponentially growing content base of semi-structured documents. They thus need to know which content to keep in which state in order to run their processes more efficiently and effectively.

Consequently, another area of intense interest is the identification of employees according to their competencies. While process managers see distinct improvement potential in using expertise directories or yellow pages, the restrictive European data protection acts and the ambiguous position of these systems in terms of human resources activities, stall such approaches in many companies. While several of our corporate research partners have isolated solutions in single departments, especially in $T$ and internal consulting, only one in the insurance industry has set up a company-wide skills management project.

To analyze the customer requirements in this project, a two-day interview session was conducted. A total of nine stakeholders, ranging from operatives to middle management with customer-oriented assignments, were interviewed in sessions ranging from 45 to 60 minutes. All the interviewees confirmed the high demand for expertise location services within their business processes and were willing to support the project financially. The stated requirements included improved transparency regarding their workforce's skills, qualifications, abilities and required trainings as well as the potential to swiftly identify required resources within other parts of the company. The main difficulties were seen in constructing a competencies base relevant to the own business process, while minimizing the effort for employees updating personal profiles.

The storage of knowledge across business processes is another area of interest for corporate research partners. While a third of the companies have large scale community structures in place, most of them concentrate on one core process, such as research and development and other areas of high expertise. In organizations that are structured along customer-oriented processes, communities of practice that span organizational team structures are not as yet

VOL. 7 NO. 52003 JOURNAL OF KNOWLEDGE MANAGEMENT | PAGE 113 
explicitly managed. The lack of possibilities with which to bridge the temporal and geographical gaps between the different customer teams is seen as a major hindering factor. Nevertheless, the role and management of these complementary organizational structure are seen as vital. One organizational partner has started a multi-million Euro project that largely focuses on enhancing its abilities to use forms of virtual work that are independent of temporal and geographical constraints, and are embedded into the existing organizational structure.

While the integration of epistemological and ontological approaches into an encompassing knowledge management model was continuing, the direct process support through knowledge management that was required by the corporate research partners and survey participants could still not be provided. This limitation was due, as previously mentioned, to the selforientation of $\mathrm{KM}$ models. To address this challenge, we proposed a framework for customer knowledge management which is described in the following sections.

\section{A CRM process model}

Based on previous research by Schmid (2001), literature research, and work with our corporate research partners, we proposed the following process model which describes business processes relevant for CRM. This model assists us in specifically identifying activity fields that are relevant for knowledge management, thus helping to improve CRM processes.

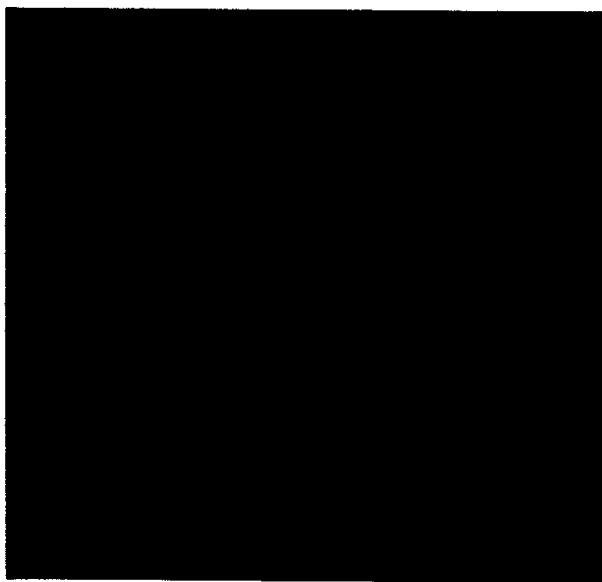

Marketing. sales, and senvice are prinary business functions (Porter, 1998) characterized by a high degree of direct customer interaction and knowiedge intensity, which makes them primary targets for CRM. We therefore derived a process model by deconstructing these functions into relevant business processes which could be cross-functional. A CRM business process involves the processing of customer kinowledge to pursue the goals of CRM. Usually it also involves direct customer contact and the exchange of information or services between the enterprise and a customer. Such processes are either triggered by a customer with the aim of receiving information or services! which involves a transter of information from the custoner 10 the enterprise, or are triggered by the enterprise with the aim of delvering infornation or services to customers. Each process is aimed at a specific business object that distinguishes it rom other processes. We identfied six relevant CRM business processes: campaign management, lead management. offer management. contract mamagemen!, complain! management, and service management.

In contrast with transaction marketing, relationship marketing is based on interactive, individualized contacts (Grönroos, 1994). Campaign management is the core marketing process which implements the ideas of relationship marketing. We define it as the planning, realization, control and monitoring of marketing activities aimed at known recipients, who are either existing or prospective customers. Marketing campaigns are individualized (one-to-one marketing) (Peppers and Rogers, 1993) or segment-specific, usually use different communication channels, and offer at least one communication channel for feedback from the recipients to allow interaction. Campaigns may be triggered by the enterprise or by a customer. The objective of campaign management is to generate valuable opportunities or "leads", which can be further qualified by lead management. An earlier approach, which focused on a one-way communication from the enterprise to the customer, was the concept of direct marketing (Nash, 1986).

Lead management is the consolidation, qualification, and prioritization of contacts with prospective customers. Contacts may be received from campaign management or other sources, e.g. the service management process. The objective is to provide sales staff with a qualified and prioritized list of presumably valuable prospective customers to allow a precise and effective address within the offer management process.

Offer management is the core sales process. Its objective is the enterprise-wide consistent creation and delivery of individualized, binding offers that fulfill all requirements for a direct conclusion. An offer management process may be triggered by a customer inquiry, a qualified lead, or an otherwise discovered opportunity. 
Contract management is the creation and maintenance of contracts for the supply of a product or service. As such, it may support offer management or service management processes in the preparation of an offer. Especially important in the service sector, contract management comprises the maintenance and adjustment of long-term contracts, e.g. for outsourcing agreements or insurance.

Within the scope of complaint management, the articulated dissatisfaction of customers is received, processed, and communicated to the enterprise (Stauss and Seidel, 2002). The objectives are to improve customer satisfaction in the short-run by directly addressing problems that led to complaints, and to feed a continuous improvement process to avoid complaints in the long-run.

Service management is the planning, realization and control of measures for the provision of services. A service is an enterprise's intangible output, generated with customers' or some of their assets' direct involvement. Examples include maintenance, repair, and support activities in the after-sales phase as well as the provision of financial or telecommunication services after the conclusion of contracts.

CRM activities and enabling factors

In addition to CRM business processes, CRM requires activities to design interfaces to customers at customer interaction points.

Interaction management is the analysis and selection of media-based communication channels, e.g. interactive voice response (IVR) or the World Wide Web (WMW), with which to achieve the optimal channel mix (Senger et al., 2002). The objective is to increase the quality and value of interactions, while simultaneously decreasing the cost of interactions by shifting customers to less costly channels, e.g. Web-self-service.

Closely connected to interaction management is channel management, which addresses the challenge of the configuration and synchronization of different communication channels (Gronover and Riempp, 2001). Its key objectives are to define organizational responsibilities for each channel, to avoid conflicts between channels, and to ensure consistent knowledge flows through different channels.

Opportunity management has a primary role as an enabling factor in the CRM context. In contrast to the rigid structure of processes such as lead management, which prioritizes valuable contacts derived mainly from campaign management, the aim of opportunity management is to realize specific opportunities discovered locally by sales and service staff (Colarelli O'Connor and Rice, 2001). This can be achieved by the expansion of employees' competencies with direct customer contact, the provision of techniques and simple rules for the identification and selection of promising opportunities (Eisenhardt and Sull, 2001).

Process-oriented knowledge management goals

We previously maintained that the self-orientation of $\mathrm{KM}$ is the main reason that many $\mathrm{KM}$ models have difficulties proving the value of managing knowledge within a business environment. This section offers a way to directly realign a KM model to business processes, in this case the CRM process framework. The resulting CKM model focuses on the management of knowledge about, for and from customers, henceforth summarized by the term "customer knowledge".

Knowledge is created, located and captured, disseminated, modified and constantly used within all CRM business processes. However, CRM does not require self-oriented knowledge

\section{c6 The customer knowledge management model focuses on the management of knowledge about, for and from customers. 99}


management processes. It requires goals for managing the knowledge critical for its business processes.

The CKM model therefore transforms the KM process perspective of ontological KM models into a KM goal perspective. The KM goal perspective offers process owners different options on which to focus when managing critical knowledge entities. The CKM goal perspective encompasses four goals (see Figure 1):

(1) Knowledge transparency supports the execution of business processes in defining their requirements concerning the manageability of customer knowledge. A high degree of manageability requires a high degree of transparency.

(2) Knowledge dissemination supports the business process owners in defining the degree of customer knowledge distribution required among all the individuals who participate in process activities. The management of dissemination requires the management of knowledge transparency.

(3) Knowledge development supports the business process in defining the requirements concerning the adaptation and creation of knowledge. Although knowledge can be created by an individual, based solely on his or her own context, from a CRM process perspective valuable customer knowledge development requires the ability to disseminate knowledge among individuals. The management of knowledge development therefore requires the management of knowledge dissemination.

(4) Knowledge efficiency is based on the diminishing marginal utility of customer knowledge. The goal of knowledge efficiency supports the business process in selecting the knowledge crucial for the CRM process from the large body of knowledge available. Knowledge efficiency requires the manageability of knowledge development, because it necessitates a high level of understanding of current and future customer needs that is essential for enhancing the CRM processes. Since it requires a decision within an uncertain environment, one of the most difficult managerial decisions is to voluntarily destroy or disregard customer knowledge, based on the understanding that this knowledge will actually hinder the knowledge flows within a business process.

Figure 1 Knowledge management (KM) goal pyramid

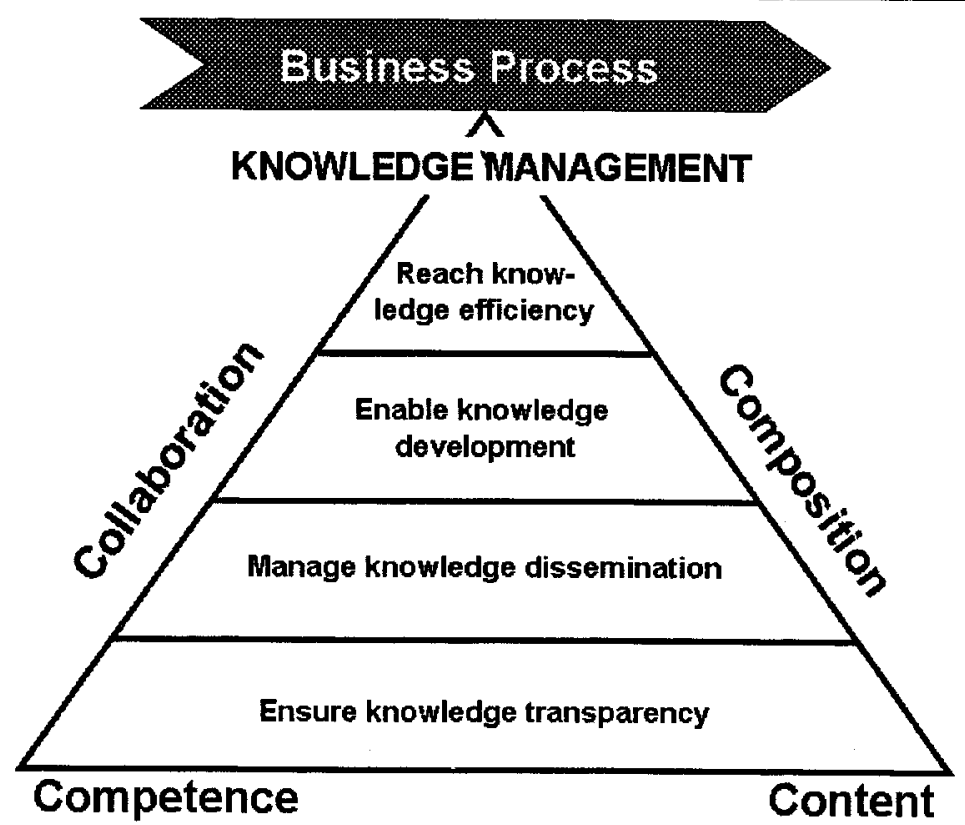

PAGE 116 J JOURNAL OF KNOWLEDGE MANAGEMENT | VOL. 7 NO. 52003 
The four management goals constitute a cascading framework for analyzing the customer knowledge requirements of a CRM business process. They are stripped of their self-orientation; they themselves do not add value, but serve as a subsystem for business processes.

\section{Managing the four aspects of knowledge}

While allowing process owners the direct articulation of their knowledge needs, the four $\mathrm{KM}$ goals do not provide operational guidelines for managing customer knowledge based on its relevant characteristics. Operational decisions regarding knowledge management within a business process should, however, take its relevant characteristics into account. Although commonly used knowledge characteristics such as implicit/explicit knowledge (Polanyi, 1966) and programmed/reflective knowledge (Revans, 1982) exist, developing an encompassing list of business-relevant knowledge characteristics is yet to be done. Beside the difficulties of structuring knowledge into discrete categories, the main drawback of this approach lies in the complex result. The SECI model consists of two knowledge characteristics with two and four parameter values for a total of eight possible combinations. This number grows exponentially with each added characteristic, leading to a matrix whose complexity prevents its use within a business environment.

Consequently, the CKM model follows a different approach by defining the relevant knowledge characteristics based on a business perspective. The goal is not a set of discrete knowledge attributes, but "chunks" of several knowledge characteristics that, combined, are relevant to business processes. Each combination of knowledge characteristics, also called a knowledge aspect, is therefore based on a specific business requirement related to the management of knowledge. The CKM model differentiates between the four knowledge aspects of content, competence, collaboration and composition:

The content aspect offers guidelines to answering the question: when should knowledge be separated from individuals and codified into information objects within a business process? Information objects are not knowledge, but massively reduced representations thereof (Riempp, 2003). Given sufficient context, an individual can reconstruct the knowledge within an information object without needing access to the originator. Codification therefore allows cost efficient storage and dissemination of knowledge. Besides documentation requirements, the value of information objects depends on the stability and longevity of the knowledge it contains as well as on the number of individuals who are able to reconstruct it.

The competence aspect concentrates on answering the question: which knowledge is required by the workforce in order to provide competitive accomplishments within the business processes? The knowledge analyzed within this aspect is generally implicit, highly volatile, context sensitive and is constantly reflected. Managing this knowledge requires the transparency of all business relevant competencies and options to enhance specific competence areas by either educating the existing workforce or by hiring new personnel.

The collaboration aspect focuses on the question: how can the knowledge within groups, such as project teams or quality circles, be effectively supported? This knowledge is different from individual knowledge as it only exists in a group context. Collaborative knowledge mainly exists in implicit form. It is volatile, as it is constantly shared between group members. Its existence is tied to the originating group and it can be supported by community management or knowledge networks.

The composition aspect represents the incorporation and cost effective dissemination of knowledge within enterprises. This requires information objects that can point to other information objects or sources of knowledge residing in individuals or groups. Referencing information objects, such as glossaries, taxonomies and metadata repositories, support users while they navigate or search for required knowledge.

The CKM model offers goals and aspects of knowledge that support the management of knowledge within a business environment. The four knowledge aspects of content, competence, collaboration and composition allow the management of knowledge based on those characteristics and dimensions that directly impact the process performance.

VOL. 7 NO. 52003 JOURNAL OF KNOWLEDGE MANAGEMENT $\mid$ PAGE 117 


\section{Towards customer knowledge management}

In practice, we observe that customer relationship management and knowledge management have considerable synergy potential (see Figure 2). While $\mathrm{KM}$ acts as a senvice provider for CRM, the interdependencies between and mutual benefits of the two approaches can result in synergies. The subjoining of knowledge management elements allows CRM to expand from its mechanistic, technology-driven and data-oriented approach, enabling it to encompass technological and people-orientation elements. Knowledge management is thereby able to directly prove its value within the process chain.

We chose the process dimension as the integration area. Because most CRM and KM research does not directly focus on the process dimension, we developed modifications to allow direct integration into a process framework. This section provides a brief overview of a joint model that balances the approaches of knowledge management and customer relationship management.

As described before, CRM manages knowledge for, from and about customers. Knowledge for customers is mainly generated in processes within the enterprise, such as in research and development and production. Campaign management is responsible for collecting this knowledge and refining it in respect of the customer requirements. It is then distributed to the other CRM processes, mainly offer management, contract management and service management. CRM manages knowledge transparency and dissemination of knowledge to customers. The main challenge when managing this kind of knowledge is maintaining the balance between comprehensibility and precision.

Knowledge about customers is mainly captured by offer management, service management, complaint management and, if available, contract management. Campaign management and service management are the main user processes of knowledge about customers, because both processes personalize their services as based on user criteria. Within the company, knowledge about customers must be transparent, although its dissemination beyond the borders of an organization must be controlled, since this knowledge can often be directly transformed into competitive advantages. The development of such knowledge is also expensive, because knowledge explication takes time and draws attention from the main task,

\section{Figure 2 Customer knowledge management (CKM) model}

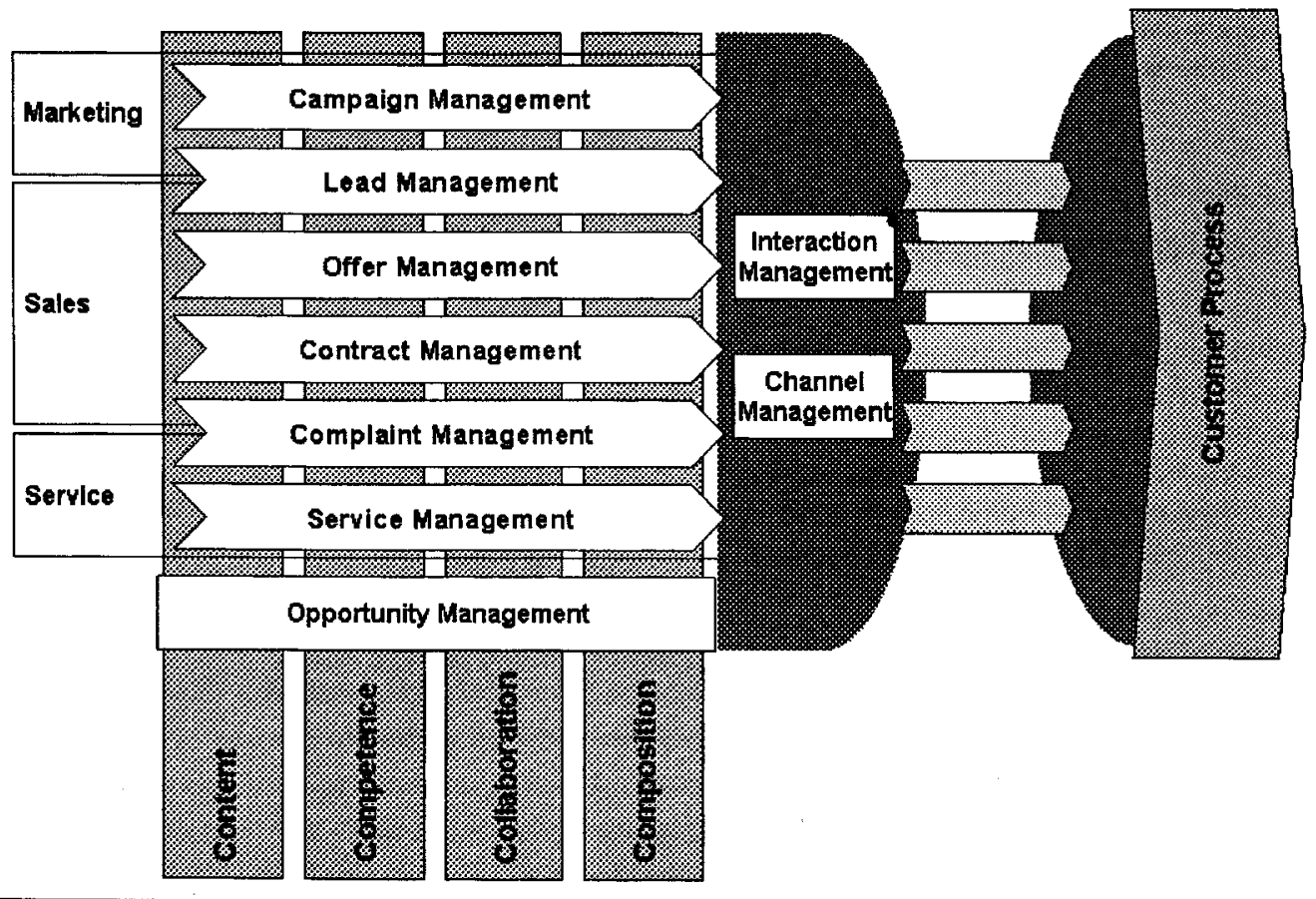

PAGE 118 | JOURNAL OF KNOWLEDGE MANAGEMENT | VOL. 7 NO. 52003 


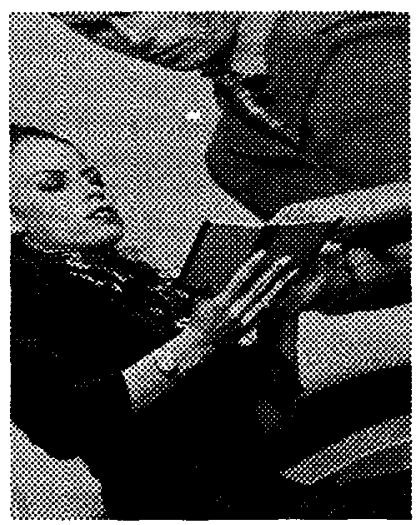

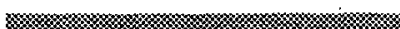

i.e. serving the customer. Interaction management offers opportunities to automatically gain knowledge about customers via the electronic media. The critical challenge when managing knowledge about the customer is the question of how much data about the customer an enterprise can transform into knowledge.

Knowledge from customers can be captured in the same ways as knowledge about customers. Gaining knowledge from customers is based on the fact that customers gain their own expertise while using a product or service, and that they can be regarded as equal partners when discussing changes or improvements. This aim is not commonly understood in business and its impact is insufficiently researched (Garcia-Murillo and Annabi, 2002). To utilize knowledge from customers as agents of change, it must be channeled into the back-end processes of an enterprise, such as the research and development processes. Although valuable knowledge from customers is mostly gained at service points, an enterprise has to analyze its CRM processes concerning their ability to serve customers. Distracting CRM from its original senvice goal in order to capture larger amounts of knowledge from customers is, however, a short-sighted goal.

The knowledge aspects support CRM to meet its primary goal of serving customers by managing knowledge for, about and from customers. The management of content thereby allows CRM process owners to focus on the messages they want customers to receive. Competence management streamlines processes, as it bridges the gap between an individual receiving a customer request and the individual solving it. Collaboration support is an aspect that allows teamwork with less time and space constrains. In turn, composition enables scaling the former three aspects beyond the team context, as navigation and search allow faster access to knowledge by using taxonomies and indexes.

The integration of CRM and KM approaches benefits both areas. Whereas the CKM model displays major integration elements, the performance benefits of the integrated approach can only be shown in specific process implementations - the following case study is an example of this.

Case study: enhancing knowledge dissemination in a customer service center

This excerpt from an action research case of a large mutual fund company (MFC) illustrates the business impact of the CKM view in a typical CRM environment. The case focuses on a major element within modem CRM concepts: a call or communication center (CCC) that integrates the communication channels (phone, fax and email) serving a geographically dispersed client base in many companies.

Because our research partner works primarily as a specialized service provider for its founding banks, the CCC serves bank employees and retail customers alike. This requires a profound knowledge of the banking and fund managing environments. The CCC employees are highly skilled, many of them having specialized degrees and multiple years of working experience within a banking environment.

The CCC has 120 employees, of whom two thirds offer the more general first level support while one third specializes in second level support of complex and dynamic knowledge areas such as funds in specific international areas.

In order to address their customer needs, CCC employees utilize different information sources. News and important information concerning services and products are provided by an internal unit called "information management" (IM). This content is largely disseminated via email. While this is possible without investments in technical infrastructure, each CCC employee must organize his or her content individually and new employees have no knowledge base to build on. The amount of content disseminated also strains the network environment because the usual informational email frequently includes up to 10 megabytes of attachments. Thus its transfer via "Simple Mail Transfer Protocol" (SMTP) to nearly 150 recipients results in a data transfer volume of up to 1.5 gigabytes per email.

IM therefore started implementing a new information channel by using basic Web technology. The resulting intranet solution, called "surfMe", was intended as a centralized platform offering

VOL. 7 NO. 52003 JOURNAL OF KNOWLEDGE MANAGEMENT | PAGE 119 
information on products and services that can be used by CCC employees when serving customers by phone.

After a year, the role of "surfMe" entered a critical stage. While the amount of content included in the system required increasing maintenance efforts by IM, it was still not fully accepted by the CCC employees: important information was not instantly available and a lack of search functions prolonged the critical time to retrieve content while serving a customer by phone.

While thinking about changing the technical infrastructure, IM raised the issue within the context of our collaborative research in order to obtain a comprehensive analysis of the challenges hindering the success of the new communication channel.

\section{Application of the CKM model}

During two one-day workshops and based on MFC's customer knowledge processes, the CKM model was used to analyze the success factors for a redesign of the existing communication channels.

The focus of the project was to provide CCC employees with knowledge for customers. Because many IM members are former CCC employees, IM has a very good overview of the knowledge available and required by the $\mathrm{CCC}$ - knowledge transparency was therefore not an issue. The main knowledge goal of the project was enhancement of knowledge dissemination. Following up the knowledge development was also regarded as important, as most knowledge used within CCC is created in other departments, such as product management and marketing. But because knowledge delivery to the CCC employees was the top priority, solving this secondary challenge was delayed until the basic solution for dissemination was operative.

After determining the knowledge goals, the relevant knowledge aspects and its manifestations were identified. The requirements of the CCC employees showed a major shortcoming in the current design of knowledge composition: the navigational structure was unmanageable, hampering the searching for content.

IM itself required improvement of the knowledge aspects content and composition. The major content challenge, requiring up to 50 percent of the time spent on "surfMe", was identified in the transformation of Microsoft Office documents into content displayable in a Web browser. The constant growth of the "surfMe" structure also required increased maintenance and tied employees to their roles as Web managers, since assigning new colleagues became increasingly expensive. Even though it was not part of the original focus, the possibility of adding the knowledge aspect competence via an expertise directory was discussed during a workshop, since the foundations of this knowledge aspect already existed within the electronic phone book, offered by "surfMe", which served as a rudimentary yellow pages system.

By using the CKM model as an analysis teol, the weaknesses of the current knowledge management configuration could be identified and communicated in a structured and coherent way. This led to the new application having a customer- and maintenance-friendly architecture. The resulting project to reengineer "surfMe" concentrated on the removal of the identified weaknesses, which had a profound impact on the requirements specification for the new technical solution. Mandatory features included flexible transformation (rendering) of office documents into HTML (Hypertext Markup Language, which can be read by Web browsers), inplace editing of documents on the server, an automatic search indexer and a navigation bar that can be managed by editors without technical skills.

\section{Summary and outlook}

In multiple cases (Kolbe et al., 2003), we observed that the management of knowledge is indeed a critical success factor for CRM. It is furthermore important that knowledge management methods that aim to support CRM are process-oriented.

Based on a literature analysis and action research, we demonstrated that CRM and KM have a high synergy potential and should be used in conjunction with each other. To achieve a successful integration we proposed a business process model for CRM, comprising the six relevant business processes: campaign management, lead management, offer management, 
contract management, service management, and complaint management. Additional activities for the implementation of the customer interface are interaction management and channel management. We also identified four relevant knowledge aspects to supplement CRM processes: content, competence, collaboration, and composition. These aspects allow a structured approach for the identification of business process improvement opportunities through $\mathrm{KM}$.

The proposed business process model for CRM provides an initial starting point for the process-oriented application of KM. However, it has insufficient granularity to allow a thorough analysis of process optimization using KM. Although the four knowledge aspects provide guidance in the discovery of optimization opportunities, they do not replace a process-oriented $\mathrm{KM}$ method, but, subject to further research, form the foundation of such a method.

To address the mentioned shortcomings, we will improve and detail the CRM process model so that it describes knowledge flows among the processes[3]. Work on a method for customer knowledge management, which aims to use the four knowledge aspects to improve CRM processes, is also underway. The main focus of our research will be the measurement and proof of tangible performance improvements that have been achieved by the application of KM instruments in CRM processes.

\section{Notes}

1. A previous version of this paper was presented at the Second Intemational Conference on Electronic Business (Gebert et al., 2002).

2. Further information is available on the Web site of the competence center Customer Knowledge Management (CC CKM, http://ccckm.iwi.unisg.ch).

3. Research work is carried out within the competence center Customer > Knowledge > Performance (CC CKP, http://ccckp.iwi.unisg.ch).

\section{References}

Boisot, M.H. (1987), Information and Organisations: The Manager as Anthropologist, Fontana/Collins, London.

Büren, A., Riempp, G. and Kutsch, O. (2001), "Best practice studie zu content in portalen" ["Best practice study of content in portals"], University of St Gallen, St Gallen, available at: http://www.iwi.unisg.ch/org/iwi iwi_pub.nsf/WwwPub|RecentGer/51BOEA3299A23251C1256BD60029B30F, 09/04/2003.

Colarelli O'Connor, G. and Rice, M.P. (2001), "Opportunity recognition and breakthrough innovation in large established firms", California Management Review, Vol. 43 No. 2, pp. 95-116.

Davenport, T.H. (1993), Process innovation Reengineering Work through Information Technology, Harvard Business School Press, Boston, MA.

Davenport, T.H., Harris, J.G. and Kohli, A.K. (2001), "How do they know their customers so well?", MIT Sloan Management Review, Vol. 42 No. 2, pp. 63-73.

Davenport, T.H. and Marchand, D. (2001), Is KM Just Good Information Management?, Financial Times Limited, No. 04/25, p. 2.

Day, G.S. (2000), Capabilities for Forging Customer Relationships, Marketing Science Institute, Cambridge, MA.

Demarest, M. (1997), "Knowledge management: an introduction", http://www.noumenal.com/marc/ km1.pdf, 09/04/2003.

Donahue, K. (2001), "Knowledge management: beyond databases", Harvard Business Management Update, Vol. 6 No. 5.

Drucker, P.F. (1999), "Knowledge worker productivity - the biggest challenge", California Management Review, Vol. 41 No. 2, pp. 79-94.

Eisenhardt, K.M. and Sull, D.N. (2001), "Strategy as simple rules", Harvard Business Review, Vol. 79 January, pp. 107-16. 
Enkel, E., Raimann, J., Seufert, A., Vassiliadis, S., Wicki, Y., Back, A. and von Krogh, G. (2000), '"MERUN materializing, experience, refining and learning in knowledge networks", Report BE HSG IWI3 No. 9, Institute of Information Management, University of St Gallen, St Gallen.

Eppler, M., Seifried, P. and Röpnack, A. (1999), "Improving knowledge intensive processes through an enterprise knowledge medium", Proceedings of the 1999 ACM SIGCPR Conference on Computer Personnel Research, ACM Press, New Orleans, pp. 222-30.

Garcia-Murillo, M. and Annabi, H. (2002), "Customer knowledge management", Journal of the Operational Research Society, No. 53, pp. 875-84.

Gebert, H., Geib, M., Kolbe, L.M. and Riempp, G. (2002), "Towards customer knowledge management integrating customer relationship management and knowledge management concepts", ICEB 2002 Conference Proceedings, Taiwan, pp. 296-8.

Gronover, S. and Riempp, G. (2001), "Kundenprozessorientiertes multi-channel-management" ["Customer process-oriented multi-channel management'], ioManagement, No. 4, pp. 25-31.

Grönroos, C. (1994), "From marketing mix to relationship marketing: towards a paradigm shift in marketing", Management Decision, Vol. 32 No. 2, pp. 4-20.

Gruber, T.R. (1993), A Translation Approach to Portable Ontology Specifications, Knowledge Systems Laboratory, Stanford, CA.

Gummesson, E. (2000), Qualitative Methods in Management Research, Sage Publications, London.

Hammer, M. and Champy, J. (1993), Reengineering the Corporation, Nicholas Brealey, London.

Harrington, H.J. (1991), Business Process Improvement: The Breakthrough Strategy for Total Quality, Productivity and Competitiveness, McGraw-Hill, New York, NY.

Hedlund, G. and Nonaka, I. (1993), "Models of knowledge management in the West and Japan", in Lorange, B., Chakravarthy, B., Roos, J. and Van de Ven, H. (Eds), Implementing Strategic Processes, Change, Learning and Cooperation, Macmillan, London, pp. 117-44.

Kolbe, L.M., Brenner, W. and Österle, H. (Eds) (2003), Customer Knowledge Management, Springer, Berlin. Levitt, T. (1983), "After the sale is over", Harvard Business Review, Vol. 63 No. 5, September/October, pp. 87-93.

McAdam, R. and McCreedy, S. (1999), "A critical review of knowledge management models", The Leaming Organization, Vol. 6 No. 3, pp. 91-100.

McLoughlin, H. and Thorpe, R. (1993), "Action learning - a paradigm in emergence: the problems facing a challenge to traditional management education and development", British Journal of Management, Vol. 4, pp. 19-27.

Nash, E. (1986), Direct Marketing, McGraw-Hill, New York, NY.

Nonaka, I. and Konno, N. (1998), "The concept of 'Ba': building a foundation for knowledge creation", Califormia Management Review, Vol. 40 No. 3, pp. 40-55.

Ordóñez de Pablos, P. (2002), "Evicence of intellectual capital measurement from Asia, Europe and the Middle East", Joumal of Intellectual Capital, Vol. 3 No. 3, pp. 287-302.

Österle, H. (1995), Business in the Information Age: Heading for new Processes, Springer, Berlin.

Parvatiyar, A. and Sheth, J.N. (2000), "The domain and conceptual foundations of relationship marketing", in Sheth, J.N. and Parvatiyar, A. (Eds), Handbook of Relationship Marketing, Sage Publications, Thousand Oaks, CA, pp. 3-38.

Peppers, D. and Rogers, M. (1993), The One to One Future - Building Relationships One Customer at One Time, Currency Doubleday, New York, NY.

Polanyi, M. (1966), The Tacit Dimension, Routledge \& Kegan Paul, Gloucester.

Porter, M.E. (1998), Competitive Advantage: Creating and Sustaining Superior Performance, Free Press, New York, NY.

Probst, G.J.B., Raub, S., Romhardt, K. and Doughty, H.A. (1999), Managing Knowledge: Building Blocks for Success, John Wiley \& Sons, Chichester.

Revans, R. (1982), The Origins and Growth of Action Learning, Krieger Publishing, Bromley. 
Riempp, G. (2003), "Von den grundlagen zu einer architektur für customer knowledge management" ["From the foundations to an architecture of customer knowledge management'], in Kolbe, L., Österle, $H$. and Brenner, W. (Eds), Customer Knowledge Management, Springer, Berilin, pp. 23-55.

Schmid, R.E. (2001), "Eine architektur für customer relationship management und prozessportale bei banken" ["An architecture of customer relationship management and process portals for banks"], Thesis, University of St Gallen, St Gallen.

Schulze, J., Thiesse, F., Bach, V. and Österle, H. (2000), "Knowledge enabled customer relationship management", in Österle, H., Fleisch, E. and Alt, R. (Eds), Business Networking: Shaping Enterprise Relationships on the Internet, Springer, Berlin, pp. 143-60.

Schwede, S. (2000), "Vision und wirklichkeit von CRM" ["Vision and reality of CRM'], Information Management \& Consulting, Vol. 15 No. 1, pp. 7-11.

Senger, E., Gronover, S. and Riempp, G. (2002), "Customer Web interaction: fundamentals and decision tree", Proceedings of Eighth Americas Conference on Information Systems (AMCIS), Association of Information Systems, Dallas, TX, pp. 1966-76.

Shani, D. and Chalasani, S. (1992), "Exploiting niches using relationship marketing", The Journal of Consumer Marketing, Vol. 9 No. 3, pp. 33-42.

Shaw, R. (1999), Measuring and Valuing Customer Relationships, Business Intelligence, London.

Stauss, B. and Seidel, W. (2002), Beschwerdemanagement: Fehier vermeiden - Leistung vertossem Kunden binden [Complaint Management: Avoiding Mistakes - Increasing Performance - Achieving Customer Lock-in], Hanser, München.

Wenger, E. (1997), Communities of Practice: Learning, Meaning, and Identity, Cambridge University Press, Cambridge.

Wiig, K.M. (1995), Knowledge Management A Trilogy - Volume 3. Knowledge Management Methods: Practical Approaches to Managing Knowledge, Schema Press, Arlington, TX. 
Notes for contributors

\section{Journal of Knowledge Management}

\section{Copyright}

Articles submitted to the journal should be original contributions and should not be under consideration for any other publication at the same time. Authors submitting articles for publication warrant that the work is not an infringement of any existing copyright and will indemnify the publisher against any breach of such warranty. For ease of dissemination and to ensure proper policing of use, papers and contributions become the legal copyright of the publisher unless otherwise agreed. Submissions should be sent to:

\section{The Editor}

Rory L. Chase, Journal of Knowled ge Management

MCB University Press, 60/62 Toller Lane, Bradford,

West Yorkshire, England BD8 9BY

Tel: (44) 1274777700 ; Fax: (44) 1274785200

\section{Editorial objectives}

The Journal of Knowledge Management is a peer-reviewed quarterly publication dedicated to the exchange of the latest research and practical information on all aspects of managing knowledge in organizations. The journal publishes original research and case studies by academic, business and government contributors on strategies, tools, techniques and technologies for Knowledge Management. The focus of this joumal is on the identification of innovative Knowledge Management strategies and the application of theoretical concepts of real-world situations.

\section{The reviewing process}

The Journal of Knowledge Management

is not a refereed journal in its true

academic sense. However, papers submitted for publication will often be read and commented on by one or more reviewers, drawn from the International Editoria! Board or elsewhere, as well as by the Editor. Papers from research or academic institutions will be traditionally reviewed. On the recommendation of reviewers, a paper will be:

- accepted, meaning that it is suitable for publication with no or only minor editorial amendments, which can be managed during the editorial process.

- revised, meaning that it is potentially suitable for publication, but needs some further work.

- rejected, meaning that it is unsuitable for publication (often because it does not fit with the editorial objectives of the journal.

The review process is a constructive one, aimed at making good contributions better.

The Journal of Knowledge Management aims, above all, for the identification and implementation of innovative change strategies to facilitate business transformation towards organizational excellence. As such, reviewers will look for:

- clarity of expression and readability.

- conformance to editorial objectives, i.e., is the paper about managing knowledge?

- implications and application: what does it all mean?

\section{Manuscript requirements}

Three copies of the manuscript should be submitted in double line spacing with wide margins. All authors should be shown and author's details must be printed on a separate sheet and the author should not be identified anywhere else in the article.

As a guide, articles should be between 5,000 and 7,000 words

in length. A title of not more than eight words should be provided. A brief autobiographical note should be supplied including full name, affiliation, e-mail address and full international contact details. Authors must supply an abstract of 100-150 words. Up to six keywords should be included which encapsulate the principal subjects covered by the article.
Where there is a methodology, it should be clearly described under a separate heading.

Headings must be short, clearly defined and not numbered. Notes or Endnotes should be used only if absolutely necessary and must be identified in the text by consecutive numbers, enclosed in square brackets and listed at the end of the article.

All Figures (charts, diagrams and line drawings) and Plates (photographic images) should be submitted in both electronic form and hard copy originals. Figures should be of clear quality, black and white and numbered consecutively with arabic numerals.

Electronic figures should be either copied and pasted or saved and imported from the origination software into a blank Microsoft Word document. Figures created in MS Powerpoint are also acceptable. Acceptable standard image formats are: .eps, .pdf, .ai and .wmf. If you are unable to supply graphics in these formats then please ensure they are .tif, .jpeg, .bmp, .pcx, . pic, .gifor.pct at a resolution of at least $300 \mathrm{dpi}$ and at least $10 \mathrm{~cm}$ wide. To prepare screenshots simultaneously press the "Alt" and "Print screen" keys on the keyboard, open a blank Microsoft Word document and simultaneously press " $C$ trl" and " $V$ " to paste the image. (Capture all the contents/windows on the computer screen to paste into MS Word, by simultaneously pressing "Ctrl" and "Print screen".)

For photographic images (plates) good quality original photographs should be submitted. If supplied electronically they should be saved as .tif or.jpeg files at a resolution of at least $300 \mathrm{dpi}$ and at least $10 \mathrm{~cm}$ wide. Digital camera settings should be set at the highest resolution/quality as possible.

In the text of the paper the preferred position of all figures and plates should be indicated by typing on a separate line the words "Take in Figure (No.)" or "Take in Plate (No.)". Supply succinct and clear captions for all figures and plates.

Tables must be numbered consecutively with roman numerals and a brief title. In the text, the position of the table should be shown by typing on a separate line the words "Take in Table IV".

References to other publications must be in Harvard style and carefully checked for completeness, accuracy and consistency. This is very accuracy and consistency. This is very important in an electronic environment
because it enables your readers to exploit the Reference Linking facility on the database and link back to the works you have cited through CrossRef. You should include all author names and initials and give any journal title in and in

You should cite publications in the text: (Adams, 1997) using the first named author's name. At the end of the paper a reference list in alphabetical order should be supplied:

For books: sumame, initials, (year), title of book, publisher, place of publication, e.g. Fallbright, A. and Khan, G. (2001), Competing Strategies, Outhouse Press, Rochester.

for book chapters: surname, initials, (year), "chapter title", editor's surname, initials, title of book, publisher, place of publication, pages, e.g. Bessley, M. and Wilson, P. (1999), "Marketing for the production manager", in Levicki, J. (Ed.), Taking the Blinkers off Managers, Broom Relm, London, pp.29-33.

For journals: surname, initials, (year), "title of article" journal name, volume, number, pages, e.g. Greenwald, E. (2000), "Empowered to serve", Management Decision, Vol. 33 No. 5. pp. 6-10.

For electronic sources: if available on line the full URL should be supplied at the end of the reference.

\section{Final submission of the article}

Once accepted for publication, the final version of the manuscript must be provided, accompanied by a 3.5" disk, Zip disk or CD-ROM of the same version labelled with: disk format (Macintosh or PC); author name(s); title of article; journal title; file name.

Alternatively, the editor may request the final version as an attached file to an e-mail.

Each article must be accompanied by a completed and signed JournalArticle Record Form available from the Editor or on http://www.emeraldinsight.com/literaticlub/jarforms.htm

The manuscript will be considered to be the definitive version of the article. The author must ensure that it is complete,

grammatically correct and without spelling or typographical errors.

In preparing the disk, please use one of the following preferred formats: Word, Word Perfect, Rich text format or TeX/LaTeX.

Technical assistance is available from Emerald's Literati Club on http://www.emeraldinsight.com/literaticlub or by contacting Mike Massey at Emerald, e-mail: mmassey@emeraldinsight.com 


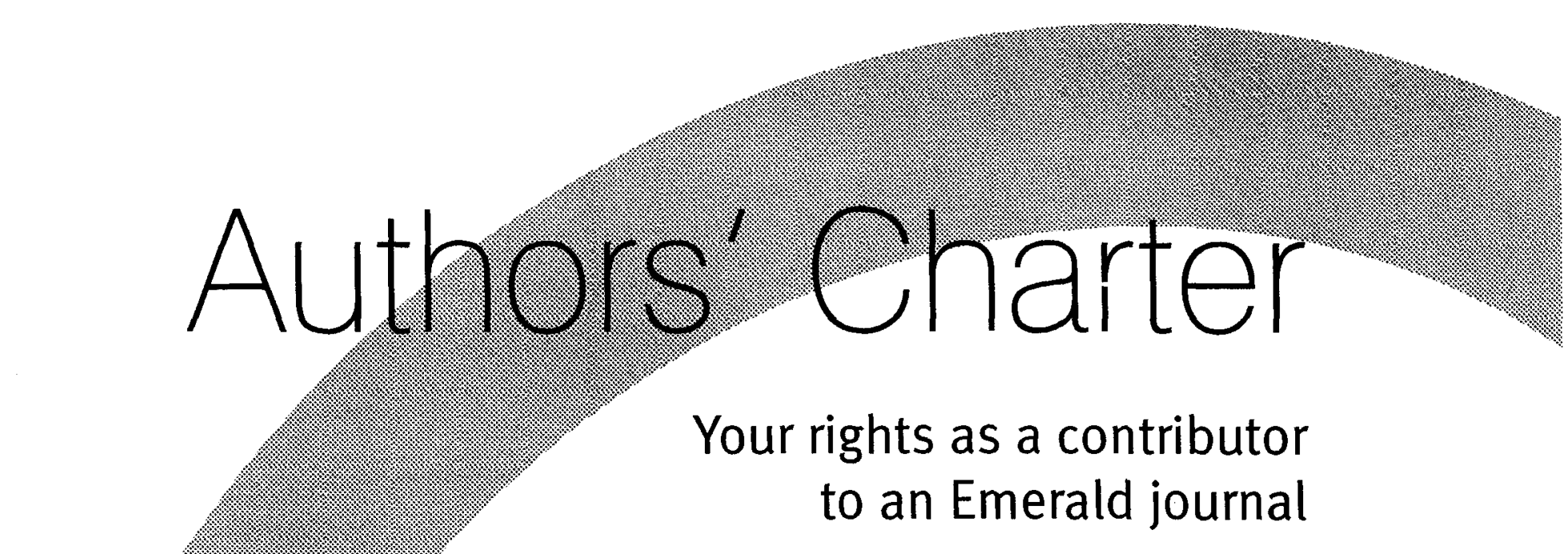

\section{Emerald's copyright principles}

Emerald* seeks to retain copyright of the articles it publishes, without the authors giving up their rights to republish or reproduce their articles on paper or electronically, subject to acknowledgment of first publication details.

\section{Emerald's commitment to you}

- An innovative publishing service which is timely, efficient, responsive and courteous

- Quality peer reviewed journals with editorial teams of distinction

- A named individual to keep you informed of publication progress

- Complimentary journal copy plus reprints plus .pdf version of your paper on request

- An editorial and production policy which encourages accuracy and reduces submission to publication times

- On-line resources, forums and conferences to assist you with your research

- Responsible rights management to promote and safeguard the integrity of your work, encourage citation and wider dissemination

- Liberal reproduction rights and premium organizations to serity

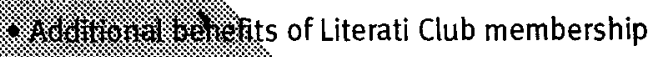

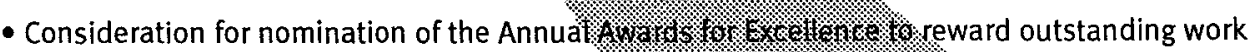

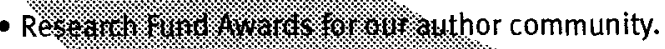

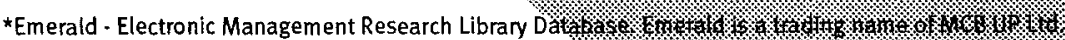

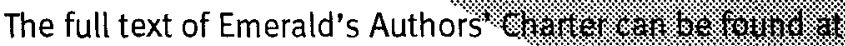

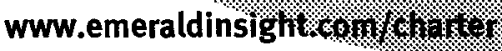

To discuss any aspect of this charter please contact us by e-mail at literaticlub@emeraldinsight.com Tel +44(o) $1274777700 \quad$ Fax +44 (o) 1274785200 Literati Club, Emerald, 60/62 Toller Lane, Bradford BD8 9BY, United Kingdom. 